\title{
Chapter 6 \\ Differential Cancer Risk in Latinos: The Role of Diet
}

\author{
Katherine L. Tucker and Kaylea Flanagan
}

\section{Introduction}

As summarized in the third expert report of the World Cancer Research Fund/ American Institute for Cancer Research (WCRF/AICR), there is accumulating evidence regarding the importance of diet to cancer risk [1]. Because new research is making contributions at a rapid pace, WCRF/AICR instituted the "Continuous Update Project" to report advances in real time. Tremendous gains in new understanding of how nutrients affect gene expression through epigenetic regulation, cell signaling, and DNA damage and repair promise to clarify the important roles of foods and nutrients on risk and course of different cancers. Important conditions affected by diet that contribute to risk include inflammation and oxidative stress. What is not well covered at this time, however, is an understanding of the dietary and biological differences across populations with diverse cultural backgrounds, which may help to explain differences in patterns of cancer incidence and mortality. In the United States, Mexican Americans and Puerto Ricans are the two largest subgroups among Latinos, yet little research has been done to address the potential differences in risk for these or other Hispanic groups. This is important, particularly as the Latino population is expected to make up $25 \%$ of the total US population by 2050 [2].

\section{Cancer Incidence Varies by Ethnicity and Gender}

Cancer is the second leading cause of death in the United States [3], and thus it is imperative that preventative dietary measures be taken to lessen its occurrence. In the United States, cancer incidence is known to vary by ethnicity and gender. Between 1999 and

K. L. Tucker $(\triangle) \cdot$ K. Flanagan

Department of Biomedical and Nutritional Sciences, University of Massachusetts Lowell, Lowell, MA, USA

e-mail: Katherine_Tucker@uml.edu 
2014 total cancer incidence rates were estimated to be about 475/100,000/year in Hispanic males, and 350/100,000/year in Hispanic females. Both of these statistics fall into the middle of incidence rates among different ethnicities in the United States, higher than that of American Indians/Alaskan Natives or Asians/Pacific Islanders, but lower than that of non-Hispanic whites or African Americans [4]. However, the incidence of specific cancers varies across groups. Latinos have higher incidence rates of liver, stomach, and gallbladder cancers, compared to non-Hispanic whites, and Latino women have among the highest incidence rates of cervical cancer $[4,5]$.

Although overall cancer rates tend to be lower among Latinos than non-Hispanic whites, cancer remains a major cause of death in this group, often discovered at later stages with higher mortality. For example, the Surveillance, Epidemiology, and End Results Program (SEER) [6] noted that, for most cancers, the incidence of localized cancers are lower for Hispanics than non-Hispanic whites, yet later stage and/or more aggressive regional or distant cancers are more common among Hispanics than nonHispanic whites for lung, colorectal, melanoma, prostate, and female breast cancers [7].

Further, risk differences exist across Latino subgroups. For example, colorectal cancer mortality is higher among Puerto Ricans than Mexican Americans, while stomach cancer mortality is higher among Mexican Americans than Puerto Ricans [7]. The likelihood that these differences may be due to modifiable exposures rather than genetic factors is suggested by differences in incidence with migration. In a comparison of age-standardized rate ratios for Puerto Ricans living on the island of Puerto Rico with Puerto Ricans living on the mainland United States, mainland Puerto Ricans had significantly higher cancer risk than island Puerto Ricans. For all sites among island Puerto Ricans, standardized rate ratios (SRR) were 0.66 (95\% $\mathrm{CI}=0.61-0.70)$ for men and $0.64(95 \% \mathrm{CI}=0.60-0.68)$ for women, with most significantly lower risk on the island for liver, prostate, and colorectal cancer among men and for breast and colorectal cancer among women [8]. Similarly, Mexican Americans have higher mortality from cancer than do Mexicans living in Mexico, including for colorectal, pancreatic, kidney, liver, and esophageal cancers. There is evidence that immigrants adopt unhealthy behaviors the longer that they are in the United States [9]. Among these unhealthy behaviors are declines in dietary quality.

\section{Dietary Factors and Cancer Risk}

Dietary factors have been noted to be one of the main contributing risk factors for cancer, particularly for colon, breast, and prostate cancers [10]. Up to one third of cancers in Western countries have been estimated to be associated with dietary factors [11]. A recent review [12] estimated that $42 \%$ of all cancers and $45 \%$ of cancer deaths in the United States may be attributed to preventable risk factors. The proportion of cancer cases attributable to specific nutrition-related risk factors were estimated to be obesity (8\%), excess alcohol (6\%), low fruit and vegetable intake (2\%), low fiber intake (1\%), and processed meat intake (1\%), with lower contributions from red meat and low calcium intake. 
Alcohol intake is one of many modifiable dietary factors that has been associated with cancer risk. The definition of an alcoholic beverage is $12 \mathrm{oz}$ of beer, $5 \mathrm{oz}$ of wine, or $1.5 \mathrm{oz}$ of distilled spirits. There is evidence that heavy drinkers (more than one drink/day for women or two drinks/day for men) have significantly increased risk for mouth, larynx, esophagus, liver, and breast cancers. In one study, heavy drinkers had a $15 \%$ increase of lung cancer risk in comparison to occasional drinkers or those who did not consume any alcohol [13]. Two thirds of adults in the United States report exceeding the moderate amount at least once per month [4].

Fruits and vegetables pose many health benefits in relation to preventing disease and maintaining overall health. High fruit and vegetable intake has been associated with lower risk of lung, colorectal, breast, esophageal, stomach, pancreatic, uterine, cervical, and ovarian cancers. Cruciferous vegetables, for example, contain phytochemicals that are thought to reduce colorectal cancer risk $[14,15]$. In one study assessing the relationship between fruit and vegetable intake and the onset of colorectal cancer, however, there was a statistically significant association between the decreased risk of prevalent colorectal adenomas only in participants who had higher intake of fruits, but not vegetables. Those authors suggested that the fiber present in fruits may be protective against colorectal adenoma and ultimately protect against colorectal cancer [16]. Antioxidant nutrients in fruits and vegetables including vitamin $\mathrm{C}$, vitamin E, selenium, carotenoids, and other phytochemicals also protect against tissue damage from oxidative stress. However, several trials of antioxidant supplements did not show protection [17], demonstrating that it is important to obtain these nutrients in their natural combinations within the food matrix.

The impact of certain B vitamins is also of interest for cancer prevention, with considerable evidence for folate. Folate is required for DNA methylation and cellular repair, and low folate has been related particularly to colorectal cancer $[13,18]$. Other research has suggested a relationship between folate deficiency and lung, cervical, breast, and brain cancers [19]. Food sources of folate include leafy greens, citrus fruits, legumes, nuts, seeds, and whole grains. Vitamin $\mathrm{B}_{6}$ has also been associated with cancer prevention; this nutrient is involved in more than 100 metabolic reactions, including those involving DNA synthesis and methylation, reducing inflammation, and reducing oxidative stress. Vitamin $\mathrm{B}_{6}$ is present in a variety of whole quality foods, such as beans, grains, meat, poultry, fish, and certain fruits and vegetables, including potatoes, bananas, and avocados. Higher vitamin $\mathrm{B}_{6}$ status, measured by pyridoxal 5' -phosphate (PLP), a vitamin B $_{6}$ biomarker, has been associated with the reduced risk of colorectal cancer [20, 21]. A systematic review and meta-analysis found that observational data supported a strong inverse association between both vitamin $\mathrm{B}_{6}$ dietary intake and PLP blood concentration and the risk of all cancers: $\operatorname{diet}(\mathrm{RR}=0.78,95 \% \mathrm{CI}=0.73-0.84), \mathrm{PLP}(\mathrm{RR}=0.66,95 \% \mathrm{CI}=0.58$ 0.76). The most prominent finding among 45 studies was the relationship between gastrointestinal cancers and vitamin $\mathrm{B}_{6}$, particularly colorectal carcinoma [22].

Red and processed meats have been identified as particular foods that contribute to carcinogenic processes. Nitrites in processed meats may be converted in the stomach to carcinogenic nitrosamines [23]. Importantly, diets high in fruits and vegetables, with vitamin $\mathrm{C}$ and phytochemicals, may slow this conversion. The 
way in which one cooks meat and how much preservatives it contains could be the potential identifiable characteristics of interest. In particular, frying, broiling, or grilling meats at high temperature creates chemicals that increase cancer risk, making braising or stewing a better choice [24]. High consumption of red and processed meats may also affect serum obesity-related inflammatory markers, and elevated iron composition in meat may be carcinogenic because it is cooked at high temperatures [25].

Another controversial nutrient for cancer risk is calcium. On the one hand, foods high in calcium may reduce the risk for colorectal cancer [26]. On the other hand, high calcium intake has also been associated with prostate cancer risk. Several meta-analyses, for example, have related high calcium intake to risk of prostate cancer [27]. Roderick and Cook [28] explain how $\mathrm{Ca}^{2+}$, the physiologically active derivative of calcium, contributes to cell growth in the body. They note that, because $\mathrm{Ca}^{2+}$ is regulated by proteins which exist in cancerous cells to protect the cell, it could be detrimental to cancer progression.

\section{Dietary Patterns and Cancer Risk}

Although specific nutrients have received the most attention in the past, newer studies focus on the totality of dietary patterns and dietary quality in relation to cancer risk. One dietary pattern, in particular, has been found to be protective of many aspects of health - the Mediterranean diet. A study by Benetou et al. [29] specifically assessed adherence to a Mediterranean diet in relation to cancer risk among 25,623 participants from Greece. A 10-point scale, based on data from a food frequency questionnaire, was used to assess compliance with a Mediterranean diet. Results showed that those who most thoroughly followed a Mediterranean diet had significantly lower incidence of cancer. Important aspects of the Mediterranean diet include abundant use of fruits, vegetables, beans, nuts, and seeds, and olive oil as the major source of fat, with moderate use of dairy and limited use of red meat. This study noted that, within this population, specifically reducing intake of meat, increasing intake of legumes and vegetables, and replacing butter with olive oil yielded a $12 \%$ decrease in the incidence of cancer [29].

While evidence for the importance of these nutritional risk factors continues to grow, most studies have been conducted with non-Hispanic whites. Understanding the specifics of Mexican and Puerto Rican American dietary habits and sources of these nutrients may help improve the overall diet of Latinos as well as prevent chronic illnesses like cancer. One factor that has hindered research on Latino diets and cancer has been the use of general food frequency questionnaires (FFQ) in the United States in large cancer studies. These questionnaires, including the Block and Willett, do not contain many Latino foods of importance. In addition, they do not consider portion sizes or recipes that are important to nutrient intakes of these groups. For this reason, when studying the Puerto Rican population in Massachusetts, we developed an FFQ to specifically include their foods, portions, and recipes [30]. 
Some lessons learned from this include the need to include foods that are widely consumed by a specific group, as well as the recipes. For example, Puerto Ricans season their rice dishes with tomato sauce and a mixture of onions and green peppers, which contribute vegetables and phytonutrients that may otherwise be overlooked. They also have significantly larger servings of white rice and lower servings of most vegetables than is assumed in the most widely used FFQ. For that reason, we added the main rice dishes to our questionnaire. Another major food for Caribbean Latinos that is completely missing in most FFQ is plantains, a starchy vegetable that contributes considerably to energy and fat intake. When compared to $24 \mathrm{~h}$ recalls, we found that our FFQ, relative to the Block FFQ improved intraclass correlations considerably; for example, the correlation for vitamin A improved from 0.04 to 0.36 and for folate from 0.31 to 0.79 . Importantly, when foods consumed heavily by a subgroup in a population are missing from the FFQ or portion sizes are grossly underestimated, there is not only poorer correlation, but actual bias in estimation compared with other groups [31].

Given the scientific evidence of the potential role that these dietary factors play in cancer incidence, it is important that an accurate assessment is taken into consideration for intervention purposes. Moreover, it is important to consider different ethnic and cultural backgrounds with relation to dietary habits. By understanding the typical diet of Mexican and Puerto Rican Americans, health professionals may be able to offer advice and other mediations in order to decrease cancer incidence in these populations.

There are also considerable differences in dietary quality across Latino subgroups. A large study was conducted in 2014 to assess the overall dietary patterns of the Hispanic and Latino communities, known as the Hispanic Community Health Study/Study of Latinos (HCHS/SOL). In 2011, these ethnic minority groups made up $16 \%$ of the total US population. Puerto Ricans, Mexicans, Dominicans, and Central Americans in general lived in the United States for longer periods of time in relation to Cubans [31]. Two 24-h dietary recalls were administered to assess dietary patterns among Puerto Ricans, Dominicans, Mexicans, and Central Americans. Puerto Ricans were reported to have the highest prevalence of obesity and higher intake of saturated fatty acids and sugar-sweetened beverages; lower intake of potassium, total fruits and vegetables, and fiber; and lowest intake of vitamins A and $\mathrm{C}$, folate, calcium, and iron than other groups. Puerto Ricans and MexicanAmericans were second in relation to Cubans for total fat intake. MexicanAmericans also had higher intakes of vitamins A and C, potassium, and fiber than other Latino groups [31].

Data from the Boston Puerto Rican Health Study support the idea that Puerto Ricans have a relatively lower nutritional status. In our earlier studies [32, 33], we noted low intakes of fruits and vegetables, whole grains, dietary fiber, folate, vitamin B6, vitamin C, and calcium, relative to recommendations, with high intakes of refined carbohydrates. The low vitamin B status was confirmed with plasma concentrations; $8 \%$ were below $5 \mathrm{ng} / \mathrm{mL}$ in folate intake, and $28 \%$ were below $30 \mathrm{nmol} / \mathrm{L}$ in PLP (vitamin $\mathrm{B}_{6}$ ). Further, in relation to neighborhood-based nonHispanic whites, Puerto Ricans had lower intake and plasma concentration of most 
carotenoids, particularly lutein-zeaxanthin (which comes mainly from green leafy vegetables), but slightly higher intake of lycopene (from tomato sauce added frequently to recipes) [34].

Food acculturation is the concept of one's dietary habits in relation to how acculturated they are with the Western diet. Batis et al. [35] used the Mexican Nutrition Survey of 1999 and the NHANES in the United States to assess Mexican dietary patterns. Mexican Americans born in Mexico had higher intakes of fruits, vegetables, and fruit juices related to all other subpopulations, with evidence of declining quality with years in the United States and even more so with the subsequent generation [35]. In contrast, evidence from Puerto Ricans shows a different pattern, at least among Puerto Ricans living in the US mainland, with higher acculturation (based on orientation to US society and English usage) associated with better, rather than worse, dietary quality [36].

The American Cancer Society recommends a healthful diet for decreasing the risk of cancer. The ideal preventative dietary intakes include at least two and a half cups of fruits and vegetables per day, reduced intakes of red and processed meat, use of whole grains instead of refined grains, and limiting intake of sugars [37] (Table 6.1). The evidence clearly suggests that most Latino groups, and particularly Puerto Ricans, are falling far short of these recommendations. Improving dietary intake in these groups will require greater attention to cultural dietary patterns, emphasizing traditional healthy foods to reduce risk of cancer along with other metabolic outcomes. Further research with appropriate dietary assessment in longitudinal studies with cancer outcomes are needed in these understudied populations to reduce the current risk and to prevent the potential for widening risk with increasing use of Western diet patterns in these groups.

Table 6.1 American Cancer Society (ACS) guidelines on nutrition and physical activity for cancer prevention [38]

ACS recommendations for individual choices

Achieve and maintain a healthy weight throughout life

- Be as lean as possible throughout life without being underweight

- Avoid excess weight gain at all ages. For those who are currently overweight or obese, losing even a small amount of weight has health benefits and is a good place to start

- Engage in regular physical activity and limit consumption of high-calorie foods and beverages as key strategies for maintaining a healthy weight

Adopt a physically active lifestyle

- Adults should engage in at least $150 \mathrm{~min}$ of moderate intensity or $75 \mathrm{~min}$ of vigorous intensity activities each week, or an equivalent combination, preferably spread throughout the week

- Children and adolescents should engage in at least $1 \mathrm{~h}$ of moderate or vigorous intensity activity each day, with vigorous intensity activity occurring at least 3 days each week

- Limit sedentary behavior such as sitting, lying down, watching television, or other forms of screen-based entertainment

- Doing some physical activities above usual activities, no matter what one's level of activity, can have many health benefits 
Table 6.1 (continued)

Consume a healthy diet, with an emphasis on plant foods

- Choose foods and beverages in amounts that help achieve and maintain a healthy weight

- Limit consumption of processed meat and red meat

- Eat at least 2.5 cups of vegetables and fruits each day

- Choose whole grains instead of refined grain products

If you drink alcoholic beverages, limit consumption

- Drink no more than one drink per day for women or two per day for men ACS recommendations for community action

Public, private, and community organizations should work collaboratively at national, state, and local levels to implement policy and environmental changes that:

- Increase access to affordable, healthy foods in communities, worksites, and schools and decrease access to and marketing of foods and beverages of low nutritional value, particularly to youth

- Provide safe, enjoyable, and accessible environments for physical activities in schools and worksites and for transportation and recreation in communities

\section{References}

1. World Cancer Research Fund. Diet, nutrition, physical activity and cancer: a global perspective. https://dietandcancerreport.org. Accessed 10 Oct 2018.

2. Cruz-Correa M, Pérez-Mayoral J, Dutil J, Echenique M, Mosquera R, Rivera-Román K, et al. Clinical cancer genetics disparities among Latinos. J Genet Couns. 2017;26(3):379-86.

3. Siegel RL, Miller KD, Jemal A. Cancer statistics, 2018. CA Cancer J Clin. 2018;68(1):7-30.

4. Centers for Disease Control and Prevention. Cancer rates by race/ethnicity and sex. 2017. https://www.cdc.gov/cancer/dcpc/data/race.htm. Accessed 4 June 2018.

5. American Cancer Society. Cancer facts \& figures 2016. Atlanta: American Cancer Society 2016. https://www.cancer.org/research/cancer-facts-statistics/all-cancer-facts-figures/cancerfacts-figures-2016.html. Accessed 10 Oct 2018.

6. Siegel RL, Fedewa SA, Miller KD, Goding-Sauer A, Pinheiro PS, Martinez-Tyson D, et al. Cancer statistics for Hispanics/Latinos, 2015. CA Cancer J Clin. 2015;65(6):457-80.

7. Haile RW, John EM, Levine AJ, Cortessis VK, Unger JB, Gonzales M, et al. A review of cancer in U.S. Hispanic populations. Cancer Prev Res. 2012;5(2):150-63.

8. Ho GY, Figueroa-Valles NR, De La Torre-Feliciano T, Tucker KL, Tortolero-Luna G, Rivera WT, et al. Cancer disparities between mainland and island Puerto Ricans. Rev Panam Salud Publica. 2009;25(5):394-400.

9. Pinheiro PS, Callahan KE, Stern MC, de Vries E. Migration from Mexico to the United States: a high-speed cancer transition. Int J Cancer. 2018;142(3):477-88.

10. McGinnis J, Foege WH. Actual causes of death in the United States. JAMA. 1993;270(18):2207-12.

11. Sharma S, Vik S, Pakseresht M, Shen L, Kolonel LN. Diet impacts mortality from cancer: results from the multiethnic cohort study. Cancer Causes Control. 2013;24(4):685-93.

12. Islami F, Goding Sauer A, Miller KD, Siegel RL, Fedewa SA, Jacobs EJ, et al. Proportion and number of cancer cases and deaths attributable to potentially modifiable risk factors in the United States. CA Cancer J Clin. 2018;68(1):31-54.

13. Bagnardi V, Rota M, Botteri E, Tramacere I, Islami F, Fedirko V, et al. Alcohol consumption and site-specific cancer risk: a comprehensive dose-response meta-analysis. Br J Cancer. 2015;112(3):580-93.

14. Talalay P, Fahey JW. Phytochemicals from cruciferous plants protect against cancer by modulating carcinogen metabolism. J Nutr. 2001;131(11):3027S-33S. 
15. Higdon JV, Delage B, Williams DE, Dashwood RH. Cruciferous vegetables and human cancer risk: epidemiologic evidence and mechanistic basis. Pharmacol Res. 2007;55(3):224-36.

16. Millen AE, Subar AF, Graubard BI, Peters U, Hayes RB, Weissfield JL, et al. Fruit and vegetable intake and prevalence of colorectal adenoma in a cancer screening trial. Am J Clin Nutr. 2007;86(6):1754-64.

17. Borek C. Dietary antioxidants and human cancer. Integr Cancer Ther. 2004;3(4):333-41.

18. Kim Y, Mason JB. Folate, epithelial dysplasia and colon cancer. Proc Assoc Am Physicians. 1995;107(2):218-27.

19. Duthie SJ, Narayanan S, Brand GM, Pirie L, Grant G. Impact of folate deficiency on DNA stability. J Nutr. 2002;132(8 Suppl):2444S-9S.

20. Zhang Y. Epidemiology of esophageal cancer. World J Gastroenterol. 2013;19(34):5598-606.

21. Gylling B, Myte R, Schneede J, Hallmans G, Häggström J, Johansson I, et al. Vitamin B-6 and colorectal cancer risk: a prospective population-based study using 3 distinct plasma markers of vitamin B-6 status. Am J Clin Nutr. 2017;105(4):897-904.

22. Mocellin S, Briarava M, Pilati P. Vitamin B6 and cancer risk: a field synopsis and metaanalysis. J Natl Cancer Inst. 2017;109(3):1-9.

23. Abid Z, Cross AJ, Sinha R. Meat, dairy, and cancer. Am J Clin Nutr. 2014;100(Suppl_1):386S-93S.

24. Joshi AD, Kim A, Lewinger JP, Ulrich CM, Potter JD, Cotterchio M, et al. Meat intake, cooking methods, dietary carcinogens, and colorectal cancer risk: findings from the Colorectal Cancer Family Registry. Cancer Med. 2015;4(6):936-52.

25. Bouvard V, Loomis D, Guyton KZ, Grosse Y, Ghissassi FE, Benbrahim-Tallaa L, et al. Carcinogenicity of consumption of red and processed meat. Lancet Oncol. 2015;16(16):1599-600.

26. Lappe JM, Travers-Gustafson D, Davies KM, Recker RR, Heaney RP. Vitamin D and calcium supplementation reduces cancer risk: results of a randomized trial. Am J Clin Nutr. 2007;85(6):1586-91.

27. Gao X, LaValley MP, Tucker KL. Prospective studies of dairy product and calcium intakes and prostate cancer risk: a meta-analysis. J Natl Cancer Inst. 2005;97(23):1768-77.

28. Roderick HL, Cook SJ. Ca2+ signalling checkpoints in cancer: remodelling $\mathrm{Ca} 2+$ for cancer cell proliferation and survival. Nat Rev Cancer. 2008;8(5):361-75.

29. Benetou V, Trichopoulou A, Orfanos P, Naska A, Lagiou P, Boffetta P, et al. Conformity to traditional Mediterranean diet and cancer incidence: the Greek EPIC cohort. Br J Cancer. 2008;99(1):191-5.

30. Tucker KL, Bianchi LA, Maras J, Bermudez OI. Adaptation of a food frequency questionnaire to assess diets of Puerto Rican and Non-Hispanic adults. Am J Epidemiol. 1998;148(5):507-18.

31. Siega-Riz AM, Sotres-Alvarez D, Ayala GX, Ginsberg M, Himes JH, Liu K, et al. Food-group and nutrient-density intakes by Hispanic and Latino backgrounds in the Hispanic Community Health Study/Study of Latinos. Am J Clin Nutr. 2014;99(6):1487-98.

32. Tucker KL. Dietary patterns, approaches, and multicultural perspective. Appl Physiol Nutr Metab. 2010;35(2):211-8.

33. Ye X, Maras JE, Bakun PJ, Tucker KL. Dietary intake of vitamin B-6, plasma pyridoxal 5' -phosphate, and homocysteine in Puerto Rican adults. J Am Diet Assoc. 2010;110(11):1660-8.

34. Bermudez OI, Ribaya-Mercado JD, Talegawkar SA, Tucker KL. Hispanic and non-Hispanic white elders from Massachusetts have different patterns of carotenoid intake and plasma concentrations. J Nutr. 2005;135(6):1496-502.

35. Batis C, Hernandez-Barrera L, Barquera S, Rivera JA, Popkin BM. Food acculturation drives dietary differences among Mexicans, Mexican Americans, and Non-Hispanic Whites. J Nutr. 2011;141(10):1898-906.

36. van Rompay MI, McKeown NM, Castaneda-Sceppa C, Falcón LM, Ordovás JM, Tucker KL. Acculturation and sociocultural influences on dietary intake and health status among Puerto Rican adults in Massachusetts. J Acad Nutr Diet. 2012;112(1):64-74.

37. Kushi LH, Doyle C, McCullough M, Rock CL, Demark-Wahnefried W, Bandera EV, et al. American Cancer Society guidelines on nutrition and physical activity for cancer prevention. CA Cancer J Clin. 2012;62(1):30-67. 
38. American Cancer Society. Summary of the ACS guidelines on nutrition and physical activity. 2016. https://www.cancer.org/healthy/eat-healthy-get-active/acs-guidelines-nutrition-physical-activity-cancer-prevention/summary.html. Accessed 10 Oct 2018

Open Access This chapter is licensed under the terms of the Creative Commons AttributionNonCommercial 4.0 International License (http://creativecommons.org/licenses/by-nc/4.0/), which permits any noncommercial use, sharing, adaptation, distribution and reproduction in any medium or format, as long as you give appropriate credit to the original author(s) and the source, provide a link to the Creative Commons license and indicate if changes were made.

The images or other third party material in this chapter are included in the chapter's Creative Commons license, unless indicated otherwise in a credit line to the material. If material is not included in the chapter's Creative Commons license and your intended use is not permitted by statutory regulation or exceeds the permitted use, you will need to obtain permission directly from the copyright holder.

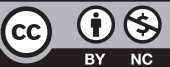

